\title{
The Evaluation of Diagnostic and Predictive Values of Helicobacter pylori Stool Antigen Test in Iranian Patients with Dyspepsia
}

\author{
Fahimeh Safarnezhad Tameshkel ${ }^{1}$, Mohammad Hadi Karbalaie Niya² ${ }^{2}$ Zahedin Kheyri $^{3}$, \\ Davood Azizi ${ }^{4}$, Farzin Roozafzai ${ }^{1}$, Samaneh Khorrami ${ }^{5,6^{*}}$
}

1. Gastrointestinal \& Liver Disease Research Center (GILDRC), Iran University of Medical Sciences, Tehran, Iran

2. Dept. of Virology, Faculty of Medicine, Iran University of Medical Sciences, Tehran, Iran

3. Dept. of Internal Medicine, Amiralmomenin hospital, Arak University of Medical Sciences, Arak, Iran

4. Dept. of Pathology, Amiralmomenin hospital, Arak University of Medical Sciences, Arak, Iran

5. Dept. of Immunology, School of Medicine, Iran University of Medical Sciences, Tehran, Iran

6. Immunology Research Center, Institute of Immunology and Infectious diseases, Iran University of Medical

Sciences, Tehran, Iran

\begin{tabular}{|c|c|}
\hline KEYWORDS & ABSTRACT \\
\hline & Background and Objectives: Iran, as a developing country, is experiencing high \\
\hline & burdens of Helicobacter pylori (Hp)-associated non-communicable diseases. Hp \\
\hline Stool Antigen Test & stool antigen test (HpSA) is widely used as an inexpensive and feasible noninvasive \\
\hline Sensitivity & method to diagnose Hp infection, instead of invasive approaches. The current study \\
\hline \multirow[t]{4}{*}{ Specificity } & $\begin{array}{l}\text { aimed at evaluating the diagnostic and predictive values of } \mathrm{HpSA} \text { test for } \mathrm{Hp} \\
\text { infection in Iranian patients with dyspepsia. }\end{array}$ \\
\hline & Methods: The current cross sectional study was performed on 100 patients with \\
\hline & dyspepsia. Gastric mucosal specimens were taken, processed, and examined \\
\hline & and sent to laboratory for further analyses. Hp stool antigen titers were assessed using \\
\hline \multirow[t]{2}{*}{ Article Info } & enzyme-linked immunosorbent assay (ELISA) technique. \\
\hline & Results: Stool antigen titers were not associated with gender $(P$-value $=0.284)$, \\
\hline Received 19 Jul 2016; & $\begin{array}{l}\text { but correlated to age }(\mathrm{r}=0.213, P \text {-value }=0.034) \text {. Considering } 0.385 \text { as a cutoff point, } \\
\text { the HpSA test had } 80.4 \% \text { sensitivity and } 85.7 \% \text { specificity. }\end{array}$ \\
\hline Accepted 01 May 2017; & Conclusion: Based on cost-effectiveness of $\mathrm{HpSA}$ test, the current study findings \\
\hline Published Online 2017; & $\begin{array}{l}\text { corroborated the use of } \mathrm{HpSA} \text { test to detect and follow-up patients with } \mathrm{Hp} \text { infection, } \\
\text { as an alternative method to detect Hp rather than invasive procedures. }\end{array}$ \\
\hline
\end{tabular}

Corresponding information: Samaneh Khorrami; Department of Immunology, School of Medicine, Iran University of Medical Sciences, Tehran, Iran. Tel: +982186703295; Fax: +982188622652; E-mail: Khorrami.s@ gmail.com

Copyright $\odot$ 2017, IRANIAN JOURNAL OF PATHOLOGY. This is an open-access article distributed under the terms of the Creative Commons Attributionnoncommercial 4.0 International License which permits copy and redistribute the material just in noncommercial usages, provided the original work is properly cited.

\section{Introduction}

Helicobacter pylori $(\mathrm{Hp})$ infection is a wellknown step in gastric cancer susceptibility and other chronic gastric diseases in adults and children (1-3). Prevalence of Hp infection varies by geographical regions, genetic background, and socioeconomic status (4-6). Reliable and accurate detection of this infection is of importance (7). Hp can be detected either invasively or non-invasively. Invasive methods, such as histopathology-based, culture, or rapid urease test (RUT), need gastric mucosa specimens obtained through endoscopy. Although invasive methods are commonly used as gold standards, studies demand less invasive or noninvasive methods such as urea breath test (UBT) and Hp stool antigen (HpSA) test (8-10).

There is not a definite method as a gold standard to detect $\mathrm{Hp}$ infection $(8,11,12)$. Diagnostic and predictive values and the cost-effectiveness of tests help to choose the optimal approach $(13,14)$. Both the UBT and HpSA tests can detect an active Hp infection, and their sensitivity is affected by the recent medications, which limits the use of noninvasive tests for a larger population (14). UBT 
is sensitive, specific, and accurate; however, it is expensive and needs trained operators. HpSA test is widely used as a simple, inexpensive, and feasible noninvasive method to diagnose and follow-up Hp infection, as an alternative method to invasive and other noninvasive approaches such as UBT $(15,16)$.

Iran, as a developing country, is experiencing high burdens of Hp-associated non-communicable diseases $(17,18)$. The current study aimed at evaluating the diagnostic and predictive values of HpSA test for Hp infection in Iranian patients with dyspepsia.

\section{Materials and Methods}

\section{Subjects}

The current cross sectional study was performed on 100 patients with dyspepsia within the age range of 20 to 70 years referred to Imam Reza Specialized Polyclinic affiliated to Arak University of Medical Sciences, Arak, Iran, from March to October 2015. All participants signed the informed consent prior to enrollment. The data pertaining demographics, medications, and medical history of patients were recorded using a questionnaire. Exclusion criteria were age under 20 years, pregnancy, post-Hp eradication, or recent use of antibiotics (within the last 2 months) or antacid medications such as proton pump inhibitors (within the last 2 weeks), and contraindications for endoscopy and biopsy such as coagulopathies. Histopathological diagnosis of $\mathrm{Hp}$ was considered as a gold standard.

\section{Endoscopy and histopathology}

Patients, sedated by a trained nurse using midazolam, underwent upper gastrointestinal endoscopy; and 2 gastric mucosal biopsies were taken from antrum and corpus according to the standard protocols. Specimens were processed and stained, using hematoxylin-eosin and Giemsa, and examined by an expert pathologist. The pathologist reported $\mathrm{Hp}$ colonization on an ordinal scale ranging from 0 (no colonization) to 3 (severe colonization).

\section{Stool samples and antigen detection}

Fresh stool samples provided in the sterile containers were immediately sent to the polyclinic laboratory. Exclusion criteria of the stool samples were diarrhea, inadequate amount and delayed delivery after collection. Examination of the stool samples to detect $\mathrm{Hp}$ antigen was performed using H. pylori $\mathrm{Ag}$ stool enzyme-linked immunosorbent assay (ELISA) kits (ACON, San Diego, USA). The manufacturer of the kit suggested the index values above 1.1 as positive.

\section{Statistical analysis}

Receiver operating characteristic (ROC) curve was drawn and the Youden $\mathrm{J}$ statistic was used to determine the optimal cutoff point. Area under curve (AUC) was analyzed. Sensitivity, specificity, accuracy, positive predictive value (PPV), negative predictive value (NPV), and diagnostic ratios were calculated for 4 cutoff points. Correlation between the age and HpSA results was evaluated using the Pearson correlation. The results of HpSA test were compared among the categories using the nonparametric Kruskal-Wallis test. P-value $<0.05$ was regarded as significant. Data were analyzed using IBM SPSS Statistics v. 22.

\section{Ethical considerations}

The study was approved by the Ethics Committee of Arak University of Medical Sciences and all patients signed the informed consent before enrollment. Researchers were committed to the principles of the Declaration of Helsinki and had no conflict of interest.

\section{Results}

The patients within the age range of 20 to 75 years (mean age $=47.51$ ) were enrolled in the study. Fortynine patients (49\%) were male. The mean HpSA test result (index value) was 1.82 (standard deviation $(\mathrm{SD})=2.02)$. Stool antigen titer was significantly correlated with age ( $\mathrm{r}=0.213$ [95\%CI: 0.012-0.394], $\mathrm{P}$-value $=0.034)$. There was no significant difference in HpSA results between the 2 genders ( $\mathrm{P}$ value $=0.284)$. Hp stool antigen titer was associated with severity of epithelial changes, particularly in males (Table 1,2). 
Table 1- Helicobacter pylori Stool Antigen Test Results Based on Gender and Epithelial Changes

\begin{tabular}{|c|c|c|c|c|}
\hline \multicolumn{3}{|c|}{ Variables } & \multirow{2}{*}{$\begin{array}{c}\text { Stool Antigen (Index Value) } \\
{[\text { Mean } \pm \text { SD] }}\end{array}$} & \multirow{2}{*}{ P-value* } \\
\hline Name & Categories & Count & & \\
\hline \multirow{2}{*}{ Gender } & Male & 49 & $1.59 \pm 1.95$ & \multirow{2}{*}{0.284} \\
\hline & Female & 51 & $2.03 \pm 2.08$ & \\
\hline \multirow{4}{*}{ Chronic gastritis $^{\dagger}$} & No & 3 & $0.17 \pm 0.09$ & \multirow{4}{*}{$<0.001$} \\
\hline & Mild & 32 & $0.36 \pm 0.90$ & \\
\hline & Moderate & 30 & $2.35 \pm 2.05$ & \\
\hline & Severe & 35 & $2.83 \pm 1.99$ & \\
\hline \multirow{4}{*}{ Intestinal metaplasia $^{\dagger}$} & No & 89 & $1.66 \pm 1.95$ & \multirow{4}{*}{0.161} \\
\hline & Focal mild & 6 & $2.90 \pm 2.22$ & \\
\hline & Focal moderate & 2 & $4.87 \pm 0.18$ & \\
\hline & Extensive & 3 & $2.35 \pm 2.60$ & \\
\hline \multirow{4}{*}{ Hp colonization ${ }^{\dagger}$} & No & 49 & $0.60 \pm 1.20$ & \multirow{4}{*}{$<0.001$} \\
\hline & Mild & 17 & $2.60 \pm 2.28$ & \\
\hline & Moderate & 17 & $3.13 \pm 1.74$ & \\
\hline & Severe & 17 & $3.25 \pm 1.87$ & \\
\hline \multicolumn{2}{|c|}{ Total } & 100 & $1.82 \pm 2.02$ & \\
\hline
\end{tabular}

CI: Confidence interval; Hp: Helicobacter pylori; SD: standard deviation

$\dagger$ Based on the histopathological findings (gold standard)

* The nonparametric Kruskal-Wallis one-way ANOVA test

Table 2- Helicobacter pylori Stool Antigen Test Results Based on Epithelial Changes in Males and Females

\begin{tabular}{|c|c|c|c|c|c|}
\hline Gender & Epithelial Change & Categories & Count & $\begin{array}{l}\text { ol Antigen (Index } \\
\text { Value) } \\
{[\text { Mean } \pm \text { SD] }}\end{array}$ & P-value* \\
\hline \multirow{12}{*}{ Male } & \multirow{4}{*}{ Chronic gastritis $^{\dagger}$} & No & 2 & $0.19 \pm 0.11$ & \multirow{4}{*}{$<0.001$} \\
\hline & & Mild & 15 & $0.16 \pm 0.06$ & \\
\hline & & Moderate & 14 & $2.04 \pm 2.09$ & \\
\hline & & Severe & 18 & $2.60 \pm 2.02$ & \\
\hline & \multirow{4}{*}{ Intestinal metaplasia $^{\dagger}$} & No & 41 & $1.19 \pm 1.64$ & \multirow{4}{*}{0.043} \\
\hline & & Focal mild & 5 & $2.87 \pm 2.49$ & \\
\hline & & Focal moderate & 2 & $4.87 \pm 0.18$ & \\
\hline & & Extensive & 1 & $-{ }^{a}$ & \\
\hline & \multirow{4}{*}{ Hp colonization ${ }^{\dagger}$} & No & 24 & $0.44 \pm 1.05$ & \multirow{4}{*}{$<0.001$} \\
\hline & & Mild & 8 & $2.45 \pm 2.46$ & \\
\hline & & Moderate & 11 & $2.73 \pm 1.85$ & \\
\hline & & Severe & 6 & $2.98 \pm 1.82$ & \\
\hline & Total & & 49 & $1.59 \pm 1.95$ & \\
\hline \multirow{13}{*}{ Female } & \multirow{4}{*}{ Chronic gastritis $^{\dagger}$} & No & 1 & $-{ }^{a}$ & \multirow{4}{*}{0.001} \\
\hline & & Mild & 17 & $0.54 \pm 1.22$ & \\
\hline & & Moderate & 16 & $2.62 \pm 2.05$ & \\
\hline & & Severe & 17 & $3.08 \pm 1.98$ & \\
\hline & \multirow{4}{*}{ Intestinal metaplasia $^{\dagger}$} & No & 48 & $2.06 \pm 2.12$ & \multirow{4}{*}{0.822} \\
\hline & & Focal mild & 1 & $-{ }^{-a}$ & \\
\hline & & Focal moderate & 0 & $-b$ & \\
\hline & & Extensive & 2 & $0.91 \pm 1.01$ & \\
\hline & \multirow{4}{*}{ Hp colonization ${ }^{\dagger}$} & No & 25 & $0.75 \pm 1.33$ & \multirow{4}{*}{$<0.001$} \\
\hline & & Mild & 9 & $2.74 \pm 2.20$ & \\
\hline & & Moderate & 6 & $3.86 \pm 1.36$ & \\
\hline & & Severe & 11 & $3.39 \pm 1.97$ & \\
\hline & Total & & 51 & $2.03 \pm 2.08$ & \\
\hline
\end{tabular}

CI: Confidence interval; Hp: Helicobacter pylori; SD: standard deviation

${ }^{\dagger}$ Based on the histopathological findings (gold standard)

* The nonparametric Kruskal-Wallis one-way ANOVA test

${ }^{a}$ One sample, no means were calculated.

${ }^{\mathrm{b}}$ No samples, no means were calculated. 
According to the gold standard, 51 patients had the grades of Hp colonization and 49 had no signs of Hp infection. First, the study used 1.100 (manufacturer's protocol) as a cutoff index value to detect Hp antigen in stool. Then, the ROC curve was drawn for HpSA test (Figure 1).

AUC was 0.851 (95\%CI: 0.772-0.931) and significant ( $\mathrm{P}$-value $<0.001$ ). Using the ROC curve, the cutoff point was 0.385 (the Youden $\mathrm{J}=0.661$ ). The study also tried 0.110 and 5.855 as the most sensitive and the most specific cutoff points, respectively. The positive and negative results for each cutoff point were cross-tabulated against the gold standard, ie, histopathology (Table 3).

Table 4 shows sensitivity, specificity, predictive values, and diagnostic ratios of $\mathrm{HpSA}$ test for each cutoff points.

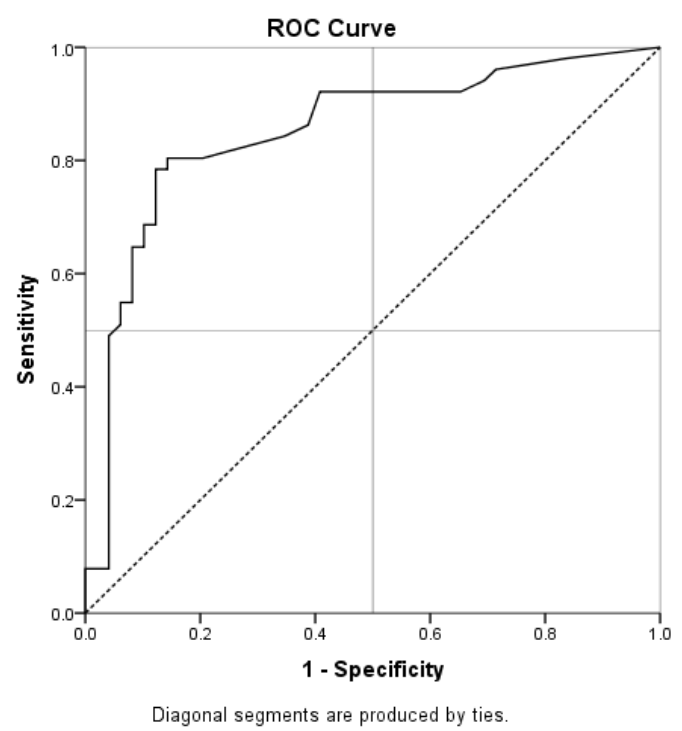

Fig 1. Receiver Operating Characteristic Curve for Helicobacter pylori Stool Antigen Test

Table 3- Positive and Negative Results for Four Cutoff Points Stool Antigen Index Values to Detect Helicobacter pylor

\begin{tabular}{|c|c|c|c|c|c|c|c|c|c|c|}
\hline & & \multicolumn{8}{|c|}{ Test Cutoff Point (Stool Antigen Index Value) } & \multirow{3}{*}{ Total } \\
\hline & & \multicolumn{2}{|c|}{0.110} & \multicolumn{2}{|c|}{0.385} & \multicolumn{2}{|c|}{1.100} & \multicolumn{2}{|c|}{5.855} & \\
\hline & & + & - & + & - & + & - & + & - & \\
\hline \multirow{2}{*}{$\begin{array}{l}\text { Hp colonization } \\
{\text { (pathology })^{a}}^{\text {pathol }}\end{array}$} & + & 50 & 1 & 41 & 10 & 40 & 11 & 1 & 50 & 51 \\
\hline & - & 41 & 8 & 7 & 42 & 7 & 42 & 0 & 49 & 49 \\
\hline Total & & 91 & 9 & 48 & 52 & 47 & 53 & 1 & 99 & 100 \\
\hline
\end{tabular}

Hp: Helicobacter pylori

${ }^{a}$ Gold standard

Table 4- Helicobacter pylori Stool Antigen Test Diagnostic and Predictive Values for Four Cutoff Points Stool Antigen Index Values

\begin{tabular}{ccccc}
\hline Test Characteristic & \multicolumn{5}{c}{ Cutoff Point (Stool Antigen Index Value) } \\
& $\begin{array}{c}\mathbf{0 . 1 1 0} \\
\text { [Most Sensitive] }\end{array}$ & $\begin{array}{c}\mathbf{0 . 3 8 5} \\
\text { [Selected] }\end{array}$ & $\begin{array}{c}\mathbf{1 . 1 0 0} \\
\text { [Predefined] }\end{array}$ & $\begin{array}{c}\mathbf{5 . 8 5 5} \\
\text { [Most Specific] }\end{array}$ \\
\hline Sensitivity (\%) & 98.04 & 80.39 & 78.43 & 1.96 \\
\hline Specificity (\%) & 16.33 & 85.71 & 85.71 & 100.00 \\
\hline Accuracy (\%) & 58.00 & 83.00 & 82.00 & 50.00 \\
\hline PPV (\%) & 54.95 & 85.42 & 85.11 & 100.00 \\
\hline NPV (\%) & 88.89 & 80.77 & 79.24 & 49.49 \\
\hline LR+ & 1.17 & 5.63 & 5.49 & $-{ }^{\mathrm{a}}$ \\
\hline LR- & 0.12 & 0.23 & 0.25 & 0.98 \\
\hline DOR & 9.75 & 24.48 & 21.96 & $-{ }^{\text {a }}$ \\
\hline
\end{tabular}

PPV: positive predictive value; NPV: negative predictive value; LR+: positive likelihood ratio; LR-: negative likelihood ratio; DOR: diagnostic odds ratio

${ }^{\text {a }}$ Unable to compute (division by 0 ) 


\section{Discussion}

Consistent with the former studies $(16,19-25)$, the current study found that HpSA test was sensitive, specific, and accurate to diagnose $\mathrm{Hp}$ infection (sensitivity: $80.4 \%$, specificity: $85.7 \%$ ). To avoid false negative results, which would be achieved if there was a history of chronic liver diseases (eg, cirrhosis), gastrointestinal bleeding, and antacid medications, the patients undergoing proton pump inhibitor or bismuth therapy were excluded. However, a few patients with asymptomatic gastrointestinal bleeding may have been included in the study, which may drive the results into the false negative HpSA tests (21). Besides, mild $\mathrm{Hp}$ colonization in the gastric mucosa accompanied by low concentrations of stool antigens could cause false negative results. Other Helicobacter species may cause false positive results (26). The condition of stool samples should be considered, too. Unformed or watery stool samples lead to less accurate test results due to diluted antigens (27).

It is challenging to define an appropriate cutoff point and test validations are important to find the optimal cutoff index for a distinct population (28, 29). The current study employed the manufacturer's cutoff index value (1.1) coming with a lower sensitivity (78.4\%) and diagnostic odds ratio (DOR) of 21.96, compared with using the new cutoff index (0.385) with sensitivity and DOR of $80.4 \%$ and 24.48 , respectively.

The HpSA test is quick, easy, patient-friendly, and inexpensive. Based on the rising trend of $\mathrm{Hp}-$ associated non-communicable diseases in Iran and the cost-effectiveness of HpSA (13), the current study findings corroborated the use of HpSA test to detect and follow-up patients with Hp infection, as an alternative to the invasive procedures.

\section{Conclusion}

According to the current study findings, the new cutoff point of 0.385 was useful when a highly sensitive test (eg, in screening) or a test with low false negative rates (eg, during follow-up) is employed to diagnose $\mathrm{Hp}$ infection in Iranian patients with dyspepsia. The use of other noninvasive methods can confirm the HpSA test results.
Recall bias and small sample size were the potential source of limitations in the current study.

\section{Conflicts of interests}

The authors declared no conflict of interest.

\section{Acknowledgements}

The current study was financially supported by Iran University of Medical Sciences, Tehran, Iran. We are thankful from Gastrointestinal \& Liver Disease Research Center (GILDRC) personnel for unaccountable technical supports and assistance.

\section{References}

1. McColl KE. Clinical practice. Helicobacter pylori infection. N Engl J Med. 2010;362(17):1597-604.

2. Zhao Y, Wang J, Tanaka T, Hosono A, Ando R, Soeripto S, et al. Association between HLA-DQ genotypes and haplotypes vs Helicobacter pylori infection in an Indonesian population. Asian Pac J Cancer Prev. 2012;13(4):1247-51.

3. Stool Antigen Tests for Helicobacter pylori Infection: A Review of Clinical and CostEffectiveness and Guidelines. CADTH Rapid Response Reports. Ottawa (ON)2015.

4. Brown LM, Thomas TL, Ma JL, Chang YS, You WC, Liu WD, et al. Helicobacter pylori infection in rural China: demographic, lifestyle and environmental factors. Int $\mathrm{J}$ Epidemiol. 2002;31(3):638-45.

5. Ghotaslou R, Milani M, Akhi MT, Nahaei MR, Hasani A, Hejazi MS, et al. Diversity of Helicobacter Pylori cagA and vacA Genes and Its Relationship with Clinical Outcomes in Azerbaijan, Iran. Adv Pharm Bull. 2013;3(1):5762.

6. Miernyk $\mathrm{K}$, Morris J, Bruden $\mathrm{D}$, McMahon B, Hurlburt D, Sacco F, et al. Characterization of Helicobacter pylori cagA and vacA genotypes among Alaskans and their correlation with clinical disease. J Clin Microbiol. 2011;49(9):3114-21.

7. Wang YK, Kuo FC, Liu CJ, Wu MC, Shih HY, Wang SS, et al. Diagnosis of Helicobacter pylori infection: Current options and developments. World J Gastroenterol. 2015;21(40):11221-35. 
8. Patel SK, Pratap CB, Jain AK, Gulati AK, Nath G. Diagnosis of Helicobacter pylori: what should be the gold standard? World J Gastroenterol. 2014;20(36):12847-59.

9. Khalifehgholi M, Shamsipour F, Ajhdarkosh H, Ebrahimi Daryani N, Pourmand MR, Hosseini M, et al. Comparison of five diagnostic methods for Helicobacter pylori. Iran J Microbiol. 2013;5(4):396-401.

10. Kalem F, Ozdemir M, Baysal B. [Investigation of the presence of Helicobacter pylori by different methods in patients with dyspeptic complaints]. Mikrobiyol Bul. 2010;44(1):29-34.

11.Lopes AI, Vale FF, Oleastro M. Helicobacter pylori infection - recent developments in diagnosis. World J Gastroenterol. 2014;20(28):9299-313.

12. Redeen S, Petersson F, Tornkrantz E, Levander H, Mardh E, Borch K. Reliability of Diagnostic Tests for Helicobacter pylori Infection. Gastroenterol Res Pract. 2011;2011:940650.

13. Schulz TR, McBryde ES, Leder K, Biggs BA. Using stool antigen to screen for Helicobacter pylori in immigrants and refugees from high prevalence countries is relatively cost effective in reducing the burden of gastric cancer and peptic ulceration. PLoS One. 2014;9(9):e108610.

14.Peng NJ, Lai KH, Lo GH, Hsu PI. Comparison of noninvasive diagnostic tests for Helicobacter pylori infection. Med Princ Pract. 2009;18(1):57-61.

15.Lario S, Ramirez-Lazaro MJ, Montserrat A, Quilez ME, Junquera F, MartinezBauer E, et al. Diagnostic accuracy of three monoclonal stool tests in a large series of untreated Helicobacter pylori infected patients. Clin Biochem. 2016;49(9):682-7.

16. Osman HA, Hasan H, Suppian R, Bahar N, Hussin NS, Rahim AA, et al. Evaluation of the Atlas Helicobacter pylori stool antigen test for diagnosis of infection in adult patients. Asian Pac J Cancer Prev. 2014;15(13):5245-7.
17. Malekzadeh F, Sepanlou SG, Poustchi H, Naghavi M, Forouzanfar MH, Shahraz S, et al. Burden of Gastrointestinal and Liver Diseases in Iran: Estimates Based on the Global Burden of Disease, Injuries, and Risk Factors Study, 2010. Middle East J Dig Dis. 2015;7:138-54.

18. Sepanlou SG, Malekzadeh F, Naghavi M, Forouzanfar MH, Shahraz S, Moradi-Lakeh M, et al. Trend of Gastrointestinal and Liver Diseases in Iran: Results of the Global Burden of Disease Study, 2010. Middle East J Dig Dis. 2015;7:12137.

19. Calik Z, Karamese M, Acar O, Aksak Karamese S, Dicle Y, Albayrak F, et al. Investigation of Helicobacter pylori antigen in stool samples of patients with upper gastrointestinal complaints. Braz J Microbiol. 2016;47(1):167-71.

20.Douraghi M, Nateghi Rostami M, Goudarzi H, Ghalavand Z. Comparison of stool antigen immunoassay and serology for screening for Helicobacter pylori infection in intellectually disabled children. Microbiol Immunol. 2013;57(11):772-7.

21.Korkmaz H, Findik D, Ugurluoglu C, Terzi Y. Reliability of stool antigen tests: investigation of the diagnostic value of a new immunochromatographic Helicobacter pylori approach in dyspeptic patients. Asian Pac J Cancer Prev. 2015;16(2):657-60.

22.Lee YC, Chiu HM, Chiang TH, Yen AM, Chiu SY, Chen SL, et al. Accuracy of faecal occult blood test and Helicobacter pylori stool antigen test for detection of upper gastrointestinal lesions. BMJ Open. 2013;3(10):e003989.

23.Lee YC, Tseng PH, Liou JM, Chen MJ, $\mathrm{Chen} \mathrm{CC}, \mathrm{Tu} \mathrm{CH}$, et al. Performance of a one-step fecal sample-based test for diagnosis of Helicobacter pylori infection in primary care and mass screening settings. J Formos Med Assoc. 2014;113(12):899-907.

24. Segamwenge IL, Kagimu M, Ocama P, Opio K. The utility of the Helicobacter pylori stool antigen test in managing dyspepsia: an experience from a low resource setting. Afr Health Sci. 2014;14(4):829-34. 
25. Sharbatdaran M, Kashifard M, Shefaee S, Siadati S, Jahed B, Asgari S. Comparison of stool antigen test with gastric biopsy for the detection of Helicobacter Pylori infection. Pak J Med Sci. 2013;29(1):68-71.

26. Ghahremani H, Farshad S, Amini Najafabadi H, Kashanian S, Momeni Moghaddam MA, Moradi N, et al. Characteristics of $26 \mathrm{kDa}$ antigen of $\mathrm{H}$. Pylori by Monoclonal Antibody. Iran J Allergy Asthma Immunol. 2015;14(1):113-9.

27. Shimoyama T. Stool antigen tests for the management of Helicobacter pylori infection. World J Gastroenterol. 2013;19(45):8188-91.
28. Raguza D, Machado RS, Ogata SK, Granato CF, Patricio FR, Kawakami E. Validation of a monoclonal stool antigen test for diagnosing Helicobacter pylori infection in young children. $\mathbf{J}$ Pediatr Gastroenterol Nutr. 2010;50(4):400-3.

29. Miftahussurur M, Yamaoka Y. Diagnostic Methods of Helicobacter pylori Infection for Epidemiological Studies: Critical Importance of Indirect Test Validation. Biomed Res Int. 2016;2016:4819423.

How to Cite This Article

Safarnezhad Tameshkel F, Karbalaie Niya MH, Kheyri Z, Azizi D, Roozafzai F, Khorrami S. The Evaluation of Diagnostic and Predictive Values of Helicobacter pylori Stool Antigen Test in Iranian Patients with Dyspepsia. Iran J Pathol. 2018;13(1):39-44. 